
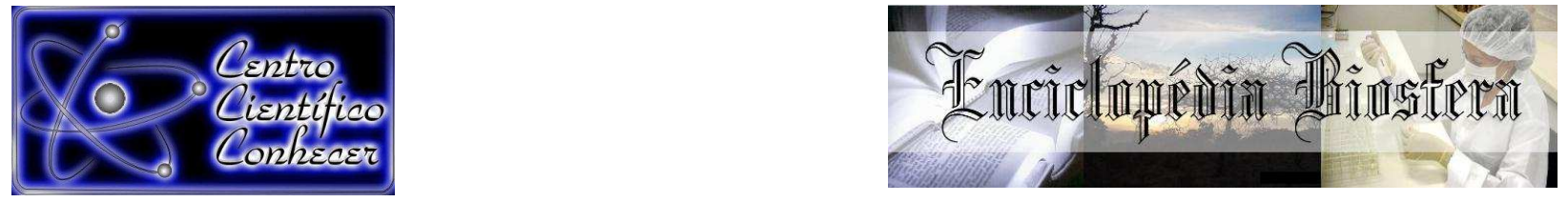

\title{
AJUSTE DE MODELOS DE REGRESSÃO PARA A ESTIMATIVA DA BIOMASSA AÉREA PARA SEIS REGIÕES DO ESTADO DO PARANÁ
}

Vitor Hugo Zanette ${ }^{1}$, Sonia Maria Kurchaidt ${ }^{2}$, Letícia Pinheiro Camargo ${ }^{3}$, Luciano Farinha Watzlawick ${ }^{4}$, Henrique Soares Koehler ${ }^{5}$.

1. Doutor em Engenharia Florestal, Professor Adjunto da Universidade Estadual do Centro-Oeste, Guarapuava, PR. zanette@unicentro.br;

2. Doutora em Engenharia Florestal, Professora Adjunta da Universidade Estadual do Centro-Oeste, Guarapuava, PR.

3. Doutora em Produção Vegetal, Engenheira de Alimentos, Universidade Estadual do Centro-Oeste, Guarapuava, PR.

4. Doutor em Engenharia Florestal, Professor Associado da Universidade Estadual do Centro-Oeste, Guarapuava, PR.

5. Doutor em Engenharia Florestal, Professor Titular da Universidade Federal do Paraná, Curitiba, PR.

\section{Recebido em: 02/10/2017 - Aprovado em: 21/11/2017 - Publicado em: 05/12/2017 DOI: 10.18677/EnciBio_2017B3}

\section{RESUMO}

O volume de biomassa florestal e sua distribuição que são fatores controladores do estoque de carbono global e servem de base para a predição futura da mudança climática tem estimulado os pesquisadores no estudo das florestas nativas para que possam conhecer cada vez mais os efeitos do carbono nestas mudanças. Neste sentido o objetivo deste trabalho foi ajustar e selecionar modelos matemáticos capazes de estimar a biomassa aérea em fragmentos de Floresta Ombrófila Mista de seis regiões do Estado do Paraná, regiões que sofreram ações de manejo em graus diferentes e estão em processo de regeneração. Estas áreas estão localizadas nos municípios de Araucária, Boa Ventura de São Roque, Castro, Coronel Vivida, General Carneiro e Reserva do Iguaçu. O estudo foi desenvolvido utilizando amostras de biomassa aérea de 382 árvores, sendo Araucária 102, Boa Ventura de São Roque 26, Castro, 42, Coronel Vivida 17, General Carneiro 172 e Reserva do Iguaçu 23 arvores coletadas por meio do método destrutivo, distribuídas nas regiões. Algumas das áreas estudadas apresentaram estatísticas de ajuste relativamente baixos, como em Boa Ventura de São Roque e Coronel Vivida, isso deve-se a diversidade de espécies e baixo número de árvores amostradas. Nas demais áreas, a maioria das equações avaliadas apresentou alto coeficiente de determinação ajustado e erro padrão da estimativa aceitável considerando que são equações para florestas naturais, podendo fornecer boas estimativas de biomassa. A equação selecionada como a mais adequada para representar as regiões foi $\left(B=a+b(\right.$ dap $\left.)+c(\text { dap })^{2}\right)$ e a equação $B=79,443-12,130$ dap $+0,655$ dap ${ }^{2}$, com $R^{2}$ igual a 0,928 , é a que melhor representa as seis áreas, e foi denominada de "EQUAÇAO PARANÁ".

PALAVRAS-CHAVE: ajustes de equações, carbono, florestas nativas. 


\title{
ADJUSTMENT OF REGRESSION MODELS FOR THE AERIAL BIOMASS ESTIMATION FOR SIX REGIONS OF THE STATE OF PARANÁ
}

\begin{abstract}
The volume of forest biomass and its distribution that are controllers of the global carbon stock and serve as a basis for the future prediction of climate change has stimulated researchers in the study of native forests so that they can become more and more aware of the effects of carbon on these changes. In this sense, the objective of this work was to adjust and select mathematical models capable of estimating the aerial biomass in fragments of Mixed Ombrophylous Forest of six regions of the State of Paraná, regions that underwent management actions in different degrees and are in the process of regeneration. These areas are located in the municipalities of Araucária, Boa Ventura de São Roque, Castro, Coronel Vivida, General Carneiro and Iguaçu Reserve. The study was carried out using aerial biomass samples from 382 trees, being Araucaria 102, Boa Ventura de São Roque 26, Castro, 42, Coronel Vivida 17, General Carneiro 172 and Reserva do Iguaçu 23 trees collected through the destructive method, distributed in the regions. Some of the studied areas presented relatively low adjustment statistics, as in Boa Ventura de São Roque and Coronel Vivida, this is due to the diversity of species and low number of trees sampled. In the other areas, most of the equations evaluated presented a high coefficient of adjusted determination and standard error of the acceptable estimate considering that they are equations for natural forests and can provide good estimates of biomass. The equation selected as the most adequate to represent the regions was $\left(B=a+b(\right.$ dap $\left.)+c(d a p)^{2}\right)$ and the equation $B=79,443-12,130$ dap + 0.655 dap $^{2}$, with $R^{2}$ equal to 0,928 , is the one that best represents the six areas, and was denominated of "EQUATION PARANÁ".
\end{abstract}

KEYWORDS: adjustments of equations, carbon, native forests.

\section{INTRODUÇÃO}

É inegável a importância da Floresta Ömbrófila Mista (FOM) no Sul do país e em especial as florestas do Paraná, notadamente nas áreas de preservação ambiental que influenciam na qualidade da água e dos rios e também no aproveitamento de plantas medicinais e de outros subprodutos não madeireiros. As florestas com araucária ocorrem predominantemente na região Sul do país e são de alta relevância econômica e oferecem diversos recursos madeireiros e outros produtos da floresta, além de serem consideradas símbolo para a região e forma de vínculo afetivo para o seu povo (PIRES et al., 2012).

A Floresta Ombrófila Mista no estado do Paraná tem remanescentes florestais em diversos níveis de preservação. Atualmente o estado possui, segundo Accioly (2013), 1.866.412,42 ha-1 de Floresta Ombrófila Mista que corresponde a $32,62 \%$ da área original em fragmentos distribuídos em quase toda a extensão do estado.

De acordo com Sonego et al. (2007), a FOM no sul do Brasil encontra-se em raros e diminutos remanescentes, muitos deles profundamente alterados e encontrados em locais de difícil acesso, como em áreas particulares ou nas poucas unidades de conservação existentes, sendo a continuidade e manutenção do sistema florestal um dos maiores desafios para os programas de conservação.

Algumas práticas contribuíram para a redução das reservas naturais de espécies desse tipo de formação vegetal. Pode-se citar a exploração intensiva de 
madeiras de grande valor econômico como a Araucaria angustifolia (pinheiro), Ocotea porosa (imbuia), Luehea divaricata (açoita-cavalo) e Cedrela fissilis (cedro) e até mesmo a exploração de produtos secundários de espécies não-madeiráveis como Dicksonia sellowiana (xaxim) e Maytenus ilicifolia (espinheira santa). Estudos sobre a composição das formações vegetais fornecem informações básicas para aplicação de técnicas de manejo florestal e estabelecimento de planos de conservação que sejam eficientes para esses ecossistemas (KANIESKI et al., 2010).

O uso do manejo sustentado nas florestas, em geral, gera benefícios ambientais pela conservação da floresta e de toda a sua biodiversidade e também benefícios socioeconômicos, pela geração de emprego e renda, bem como por meio da recomposição de áreas degradadas, filtros biológicos para purificação da água ou a realização de projetos que se relacionem com extrativismo de produtos não madeiráveis (WATZLAWICK et al., 2012).

Verificou-se também o aumento do número de estudos e análises referentes não somente à preservação da biodiversidade das áreas florestais no planeta, mas também relacionados ao clima. As conclusões mostraram que a concentração do dióxido de carbono $\left(\mathrm{CO}_{2}\right)$ e a temperatura da atmosfera aumentaram conjuntamente nas últimas dezenas de milhares de anos provocando mudanças climáticas (SILVEIRA et al., 2008).

Nesse sentido, buscam-se cada vez mais estratégias para redução da concentração de $\mathrm{CO}_{2}$ atmosférico, dentre elas pode-se citar a redução das emissões por queima de combustíveis fósseis, a redução da queima de material vegetal e o sequestro de carbono pelo plantio de florestas (CARVALHO et al., 2010).

O volume de biomassa florestal e sua distribuição são fatores controladores do estoque de carbono global e servem de base para a predição futura da mudança climática. Assim, torna-se necessário desenvolver ou utilizar metodologias que possibilitem a obtenção de estimativas da quantidade desse elemento em uma floresta, em diferentes partes de uma árvore. Como a maioria dos fenômenos naturais tem comportamento não-linear, a utilização de modelos não-lineares produz estimativas mais exatas do que os lineares (SANTOS, 1996). Em se tratando de manejo florestal é indicado o uso de modelos não-lineares fundamentando-se no crescimento de uma árvore individual e em consequência, da floresta, que tem tendência não-linear e sigmoidal (REGAZZI, 1993).

A utilização de equações de regressão é vantajosa, pois são obtidas estimativas de biomassa sem a necessidade de utilizar métodos destrutivos. Porém, uma desvantagem do método é que geralmente não se tem dados de todas as classes de diâmetro, considerando que os inventários florestais visam somente a parte comercial de uma floresta, desprezando árvores pequenas e que podem representar até 30\% da biomassa de uma floresta (BROWN, 1997).

Para um conjunto de dados podem ser ajustados diversos modelos de regressão e a seleção de uma equação pode ser feita utilizando critérios estatísticos, como o coeficiente de determinação, o erro padrão da estimativa, a distribuição dos resíduos e a estatística $\mathrm{F}$ (SCHNEIDER, 1997).

Assim, o objetivo deste trabalho foi ajustar e selecionar modelos matemáticos capazes de estimar a biomassa aérea em fragmentos de Floresta Ombrófila Mista de seis regiões do Estado do Paraná, localizadas nos municípios de Araucária, Boa Ventura de São Roque, Castro, Coronel Vivida, General Carneiro e Reserva do Iguaçu, os resultados obtidos no presente estudo poderão integrar planos de manejo e derrubadas de árvores das regiões estudadas, permitirão alimentar os bancos de 
dados com medidas obtidas em áreas que compreendam, por exemplo, $\mathrm{PCHs}$ (Pequenas Centrais Hidrelétricas), além de fornecer uma equação que representa a estimativa de biomassa aérea para o Estado do Paraná, com a junção das seis áreas em estudo.

\section{MATERIAL E MÉTODOS}

No presente estudo foram amostradas 382 árvores e anotados os valores do diâmetro a altura do peito (dap) e da biomassa aérea seca proveniente de seis áreas amostrais implantadas em fragmentos de Floresta Ombrófila Mista, nos municípios de Araucária, Boa Ventura de São Roque, Castro, Coronel Vivida, General Carneiro e Reserva do Iguaçu, no Estado do Paraná. Os fragmentos florestais onde estão instaladas as áreas experimentais possuem variadas topografias, solos e níveis de antropização, mas todas encontravam-se em estágio secundário de sucessão, classificadas conforme a Resolução n² - CONAMA/1994 (BRASIL, 1994).

A área experimental de Araucária tem 20 parcelas de $10 \times 10 \mathrm{~m}$, está localizada próxima à Refinaria Presidente Getúlio Vargas, pertencente à PETROBRÁS, na porção Centro-Sul do primeiro planalto paranaense, município de Araucária, com as seguintes coordenadas: Latitude 25³5'12"S e Longitude 49²0'45'W. A área em questão sofreu grandes modificações por conta da Refinaria, no entanto a vegetação encontra-se em bom estado de conservação, com características originais da Floresta Ombrófila Mista Aluvial.

A área localizada no município de Boa Ventura de São Roque, faz parte de um fragmento de Floresta Ombrófila Mista particular com aproximadamente 5 hectares, com 50 parcelas de $100 \mathrm{~m}^{2}$ e coordenadas geográficas: Latitude 244ㄱ'34'S e Longitude 51 $30^{\prime} 49^{\prime \prime} \mathrm{W}$. O fragmento florestal sofreu grande exploração no passado, quando foram retiradas as espécies florestais de maior valor econômico, seguido da criação de gado sob a floresta remanescente. Porém, há 15 anos não é explorada de nenhuma forma. Segundo a classificação do IBGE (2012), a vegetação da região é a Floresta Ombrófila Mista Montana.

A área experimental situada no município de Castro, com 0,5 ha em 50 parcelas de $100 \mathrm{~m}^{2}$, está inserida em um fragmento de Floresta Ombrófila Mista situado no Sítio Pau Brasil, localidade Campo do Meio, coordenadas geográficas: Latitude $24^{\circ} 57^{\prime} 03^{\prime \prime} S$ e Longitude $49^{\circ}$ A vegetação predominante encontrada é a Floresta Ombrófila Mista Montana (IBGE, 2012).

A área localizada no município de Coronel Vivida, com 0,5 ha em 50 parcelas de $100 \mathrm{~m}^{2}$ está instalada no sítio Recanto das Cachoeiras e apresenta como coordenadas geográficas: Latitude $25^{\circ} 57^{\prime} 31^{\prime \prime S}$ e Longitude $52^{\circ} 35^{\prime 2} 21^{\prime \prime} \mathrm{W}$. A vegetação encontrada é a Floresta Ombrófila Mista Montana (IBGE, 2012).

A área experimental do município de General Carneiro, com 20 parcelas de 12 x 12m, tem como coordenadas geográficas: Latitudes $26^{\circ} 20^{\prime} 35^{\prime \prime} S$ e $26^{\circ} 26^{\prime} 13^{\prime \prime} S$ e Longitudes $51^{\circ} 19^{\prime} 49^{\prime \prime} \mathrm{W}$ e $51^{\circ} 25^{\prime} 29^{\prime \prime} \mathrm{S}$. A vegetação natural da área corresponde à Floresta Ombrófila Mista Montana (IBGE, 2012).

A área experimental localizada no município de Reserva do Iguaçu, com 0,5 ha em 50 parcelas de $100 \mathrm{~m}^{2}$, é um fragmento de Floresta Ombrófila Mista que está nas seguintes coordenadas geográficas: Latitude $25^{\circ} 49^{\prime} 02$ "S e Longitude $52^{\circ} 06^{\prime} 27^{\prime \prime} \mathrm{W}$. A área foi explorada com a retirada de espécies florestais para produção de palanques e madeiras de construção civil e com a criação de javalis. Porém, desde de 2005, não foi mais explorada. A vegetação encontrada na região é a Floresta Ombrófila Mista Montana (IBGE, 2012). 
A amostragem para a determinação da biomassa foi realizada utilizando o método da árvore individual. As árvores derrubadas para a amostragem da biomassa florestal foram separadas em compartimentos: madeira do fuste, folhagem, galhos vivos, galhos mortos, casca do fuste e miscelânea (frutos, flores e sementes). Com os dados provenientes da biomassa verde, teor de umidade para cada componente de cada árvore abatida realizou-se os cálculos da biomassa seca, sendo que cada um desses componentes foi devidamente pesado e utilizado para cálculo do total de biomassa aérea seca em $\mathrm{kg}$ por árvore, por meio da fórmula:

$$
\mathrm{BS}=\mathrm{BV} \times 1(-\mathrm{Um})
$$

Onde: $\mathrm{BS}=$ biomassa seca $(\mathrm{kg})$; $\mathrm{BV}=$ biomassa verde $(\mathrm{kg})$; $\mathrm{Um}=$ teor de umidade $(\%)$.

A base de dados utilizada no ajuste das equações de biomassa foi composta por 382 árvores, sendo 102 na região de Araucária, 26 em Boa Ventura de São Roque, 42 em Castro, 17 em Coronel Vivida, 172 em General Carneiro e 23 em Reserva do Iguaçu. As famílias mais representativas são a Euphorbiaceae com 86 árvores presentes em 5 regiões; Myrtaceae com 54 indivíduos, aparecendo em 4 regiões; em 3 regiões são encontradas as famílias: Lauraceae com 29 árvores, Aquifoliaceae com 26 amostras e Primulaceae com 24 indivíduos. As famílias Araucariaceae e Styraceae estão presentes apenas em General Carneiro com 15 e 10 árvores, respectivamente; Sapindaceae foi encontrada em 4 regiões com 15 indivíduos; 13 árvores da família Asteraceae foram observadas em 3 regiões. A família Fabaceae - Mimosoideae está presente com 11 indivíduos em 3 regiões. As famílias Salicaceae e Anacardiaceae foram observadas com 9 indivíduos presentes em 4 e 3 regiões, respectivamente; Fabaceae - Faboideae com 7 árvores aparecendo em 4 regiões estudadas; Symplocaceae foi observada com 6 árvores em 2 regiões e em 3 regiões estudadas foram observadas as famílias das Annonaceae e Rosaceae com 5 e 4 árvores respectivamente. As demais famílias foram observadas nas diferentes regiões com números de observações iguais ou inferiores a três, das quais todas foram utilizadas no ajuste das equações para cada uma das áreas e na avaliação gráfica dos resíduos. Dentre os inúmeros modelos de regressão consagrados na literatura, foram escolhidos seis modelos matemáticos de regressão para estimativa da biomassa florestal que se encontram no quadro 1.

\begin{tabular}{cc} 
QUADRO 1 & $\begin{array}{c}\text { Modelos matemáticos utilizados no ajusde de equações de } \\
\text { biomassa em seis regiões de floresta ombrofila mista no } \\
\text { estado do Paraná }\end{array}$ \\
\hline Equação & Modelo matemático \\
\hline 1 & $\ln B=a+b \cdot \ln ($ dap $)$ \\
\hline 2 & $B=a+b \cdot($ dap $)+c \cdot(\text { dap })^{2}$ \\
\hline 3 & $B=a \cdot e^{(\text {dap })^{b}}$ \\
\hline 4 & $B=a \cdot(\text { dap })^{b}+c \cdot \ln ($ dap $)$ \\
\hline 5 & $B=a \cdot e^{b+c \cdot \ln (\text { dap })+d \cdot \ln (\text { dap })^{2}+m \cdot \ln (\text { dap })^{3}}$ \\
\hline 6 & $B=a+\left(1+b \cdot e^{[c \cdot(\text { dap })]^{d}}\right.$
\end{tabular}

FONTE: os autores (2017) em que B: peso da biomassa; dap: diâmetro à 1,3 m; ln: logaritmo natural; $a, b c, d, f$, m: coeficientes estimados por regressão.

Os ajustes das equações, a confecção das estatísticas e dos gráficos foram realizadas utilizando-se os softwares Microsoft Excel 2013, MatLab ${ }^{\circledR}$ versão 2015a e ENCICLOPÉDIA BIOSFERA, Centro Científico Conhecer - Goiânia, v.14 n.26; p.33 
Statistica ${ }^{\circledR}$ versão 5.1 . O critério para seleção das melhores equações foi dado por quatro avaliadores do ajuste: maior Coeficiente de Determinação Ajustado $\left(R_{a j}^{2}\right)$, seguido do menor Erro Padrão da Estimativa $\left(S_{y x\left(\% \xi^{*}\right)}\right.$, maior estatística $\mathrm{F}$ e análise gráfica da distribuição dos resíduos padronizados. Foi também considerado a proposta de Thiersch (1997), na qual a seleção dos modelos considera o valor ponderado (VP) obtidos pelos escores de cada estatística tomadas em conjunto, em que foram atribuídos valores de 1 a 6 para cada parâmetro estatístico $\left(R_{a j}^{2}, S_{y x(\%)}\right.$, $F$ ). Para as melhores estatísticas foram atribuídos valor 1 , em seguida valor 2 até a última com valor 6 e em caso de empate as estatísticas receberam o mesmo valor.

Após a escolha do melhor modelo ajustado de cada área, foi realizada uma validação das equações, sendo utilizados os dados de uma determinada área para validar a equação de outra, escolhidas duas a duas aleatoriamente e formando seis grupos para análise dentre 15 possíveis. A validação foi realizada com esse critério, pois algumas das áreas estudadas têm um número muito reduzido de árvores amostradas que inviabilizaria realizar as validações com uma fração dos dados observados na própria área analisada. Desse modo, considerando a composição florestal única (Floresta Ombrófila Mista), optou-se por utilizar os dados de diferentes áreas, duas a duas, para a validação dos modelos obtidos.

A base de dados utilizada na validação para a área do Paraná foi composta por dados de 38 árvores, ou seja, 10\% da base de dados total, de modo análogo à metodologia apresentada por Ratuchne (2015).

\section{RESULTADOS E DISCUSSÃO}

A amostra da Floresta Ombrófila Mista estudada no presente trabalho possui 382 indivíduos pertencentes a 42 famílias. As famílias mais representativas são a Euphorbiaceae com 86 árvores presentes em 5 regiões; Myrtaceae com 54 indivíduos, aparecendo em 4 regiões; em 3 regiões são encontradas as famílias: Lauraceae com 29 árvores, Aquifoliaceae com 26 amostras e Primulaceae com 24 indivíduos.

Em São João do Triunfo/PR, Longhi (1980), encontrou 26 famílias, amostrando indivíduos com dap de $20 \mathrm{~cm}$. Na mesma floresta, após 19 anos, Pizatto (1999) encontrou 30 famílias com dap de $10 \mathrm{~cm}$. Em 2003, Watzlawick, ao analisar a Floresta Ombrófila Mista de General Carneiro encontrou 21 famílias. Socher (2004) observou 16 famílias em 2001 e 15 famílias em 2003 quando estudou um fragmento de Floresta Ombrófila Mista Aluvial na região de Araucária/PR. Ratuchne (2015) estudando 4 fragmentos de Floresta Ombrófila Mista no Paraná encontrou entre 44 e 62 espécies. Esses estudos envolveram a análise fitossociológica das áreas e não só a biomassa.

Considerando o diâmetro a altura do peito (dap) de cada árvore amostrada destaca-se a área de Coronel Vivida com (17) árvores amostradas e Boa Ventura de São Roque (26) em contraponto ao elevado número de arvores na área de General Carneiro (172). Quanto à média dos daps observou-se que variaram de $9,09 \mathrm{~cm}$ (Araucária) a 23,71 cm (General Carneiro). O maior desvio padrão $(16,46 \mathrm{~cm})$ foi observado na área de General Carneiro. O coeficiente de variação (CV\%) variou de $32,93 \%$ (Coronel Vivida) a $84,21 \%$ (Paraná). A amplitude total ficou entre $14,42 \mathrm{~cm}$ (Coronel Vivida) e 101,45 cm (Paraná), com mínimo de 4,23 cm para Castro e Paraná e, máximo de 105,68 cm para General Carneiro e Paraná. 
Figueiredo Filho et al. (2010) fizeram um levantamento de resultados obtidos em trabalhos realizados com a Floresta Ombrófila Mista no Sul do Brasil, de 1999 a 2010 e observaram que o dap teve pequena variação entre as áreas avaliadas, com o menor em São Francisco de Paula - 21,45 cm (GOMES, 2005) e o maior em São João do Triunfo - 35,90 cm (SCHAAF, 2001). A média das medidas de dap encontrada pelos autores foi de $22,63 \mathrm{~cm}$, valor maior que a média determinada no presente trabalho para o Estado do Paraná, que foi de $15,90 \mathrm{~cm}$.

Kurchaidt (2014), analisando dados de quatro parcelas permanentes no município de São João do Triunfo, encontrou no ano de 1995, dap médios variando de $10,30 \mathrm{~cm}$ a $26,60 \mathrm{~cm}$ e no ano de 2010, dap médios variando de $9,78 \mathrm{~cm}$ a $25,6 \mathrm{~cm}$.

Com relação à biomassa, observou-se que a média variou de $20,45 \mathrm{~kg}$ (Coronel Vivida) a $345,12 \mathrm{~kg}$ (General Carneiro). A amplitude de variação das medidas de desvio padrão foi de $16,40 \mathrm{~kg}$ a $800,90 \mathrm{~kg}$. O coeficiente de variação dos valores de biomassa das áreas foi bastante elevado de maneira geral, variando de $80,20 \%$ (Coronel Vivida) a 326,12\% (Paraná). A amplitude total dos dados ficou entre 68,78kg (Coronel Vivida) e 5.929,60 kg (Paraná), com valor mínimo para a biomassa de $0,65 \mathrm{~kg}$ para Coronel Vivida e máximo de 5.930,25 kg para o Paraná.

Ratuchne (2010) estudou uma área de Floresta Ombrófila Mista com Araucária no município de General Carneiro, com 91 árvores, encontrou uma média de 391,75 kg/árvore de biomassa, valor bem próximo ao determinado no presente trabalho para o mesmo município, que foi de 345,12 kg/árvore em média.

Os modelos ajustados, para escolha da melhor equação, levaram em consideração os valores obtidos nas estatísticas de ajuste, e as Equações 2 e 3 se destacaram, conforme descrito a seguir.

As melhores estatísticas para a EQUAÇÃO 2, foram: Araucária com $R_{a j}^{2}$ de $0,903, S_{y x(\% \text { : }}$ de $34,43 \%$ e $F$ de 471,82 ; Castro, com $R_{a j}^{2}$ de $0,867, \mathrm{~s}_{y x(\%)}$ de $34,95 \%$ e F de 130,17; Reserva do Iguaçu, com $R_{a j}^{2}$ de $0,811, S_{y x(\% \text {. }}$ de $51,37 \%$ e $F$ de 48,26; General Carneiro, que é a região com o maior número de indivíduos (172), o $R_{a j}^{2}$ foi $0,931, \mathrm{~S}_{y x(9)}$ de $61,88 \%$ e $F$ de $1.157,95$ sendo considerada a região de melhor ajuste.

As regiões onde a EQUAÇÃO 3 apresentou os melhores resultados foram: Boa Ventura de São Roque com $R_{a j}^{2}$ de $0,244, S_{y x(\%)}$ de $81,48 \%$ e F de 9,08 e Coronel Vivida com $R_{a j}^{2}$ de $0,672, S_{y x(\%)}$ de $45,92 \%$ e F de 33,81 .

Destaca-se que na área Boa Ventura de São Roque os ajustes de todas as equações testadas foram muito abaixo do esperado, dificultando a seleção, na área de Coronel Vivida todos os modelos apresentaram alto erro padrão da estimativa, ou baixo coeficiente de determinação, fornecendo estimativas de baixa exatidão. A justificativa para esses baixos valores é a diversidade de espécies na área estudada, a qual apresenta 26 e 17 árvores respectivamente, sendo todas de espécies distintas.

Com o agrupamento de todas as áreas, representando o estado do Paraná, os melhores resultados foram observados também na EQUAÇÃO 2, com valor de $R_{a j}^{2}$ igual a $0,928, S_{y x(\%)}$ de $85,83 \%$ e F de $2.229,86$.

A seleção dos modelos com base na proposta de Thiersch (1997), que considera o valor ponderado (VP) obtidos pelos escores de cada estatística tomadas 
em conjunto, é apresentada na Tabela 1, em que foram atribuídos valores de 1 a 6

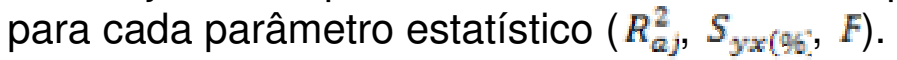

Com base nos resultados de VP, foi verificado maior desempenho na EQUAÇÃO 2 para as regiões de Castro, General Carneiro e Reserva do Iguaçu. Para a região de Araucária a EQUAÇÃO 2 e a EQUAÇÃO 4 apresentaram mesmo VP. Para Boa Ventura de São Roque, a EQUAÇÃO 3 apresentou o melhor VP, sendo que a EQUAÇÕES 1 e 2, empataram com o mesmo VP na segunda posição. $\mathrm{Na}$ região de Coronel Vivida, o melhor VP foi o da EQUAÇÃO 3, em segundo lugar a EQUAÇÃO 4, sendo a EQUAÇÃO 2 classificada como terceiro melhor VP.

Considerando as equações para o PARANÁ, a EQUAÇÃO 2 apresentou o melhor VP. Avaliando ainda um somatório do ranqueamento de todas as regiões, a EQUAÇÃO 2 apresentou o melhor VP global (43), seguido da EQUAÇÃO 4 (VP = $52)$, sendo que a EQUAÇÃO 5 foi aquela que teve o menor desempenho $(V P=101)$.

TABELA 1 - Valores ponderados dos escores dos parâmetros estatísticos para as equações de biomassa total em seis regiões de floresta ombrofila mista no estado do Paraná.

\begin{tabular}{|c|c|c|c|c|c|c|c|}
\hline Área & Estat. & EQ.1 & EQ. 2 & EQ. 3 & EQ. 4 & EQ. 5 & EQ. 6 \\
\hline \multirow{4}{*}{ Araucária } & $R_{a j}^{2}$ & 6 & 1 & 5 & 4 & 3 & 1 \\
\hline & $S_{y x \%}$ & 2 & 3 & 6 & 1 & 5 & 4 \\
\hline & $\mathrm{F}$ & 2 & 4 & 1 & 3 & 6 & 5 \\
\hline & VP & 10 & 8 & 12 & 8 & 14 & 10 \\
\hline \multirow{4}{*}{$\begin{array}{c}\text { Boa } \\
\text { Ventura }\end{array}$} & $R_{a j}^{2}$ & 5 & 2 & 1 & 3 & 6 & 4 \\
\hline & $S_{y x \%}^{2}$ & 1 & 3 & 2 & 4 & 6 & 5 \\
\hline & $\mathrm{F}$ & 2 & 3 & 1 & 4 & 6 & 5 \\
\hline & VP & 8 & 8 & 4 & 11 & 18 & 14 \\
\hline \multirow{4}{*}{ Castro } & $R_{a j}^{2}$ & 6 & 1 & 2 & 3 & 5 & 4 \\
\hline & $S_{y x \%}$ & 6 & 1 & 2 & 3 & 4 & 5 \\
\hline & $\mathrm{F}$ & 4 & 2 & 1 & 3 & 6 & 5 \\
\hline & VP & 16 & 4 & 5 & 9 & 15 & 14 \\
\hline \multirow{4}{*}{$\begin{array}{l}\text { Coronel } \\
\text { Vivida }\end{array}$} & $R_{a j}^{2}$ & 6 & 4 & 1 & 2 & 5 & 3 \\
\hline & $S_{y x \%}$ & 6 & 3 & 2 & 1 & 5 & 4 \\
\hline & $\mathrm{F}$ & 5 & 2 & 1 & 3 & 6 & 4 \\
\hline & VP & 17 & 9 & 4 & 6 & 16 & 11 \\
\hline \multirow{4}{*}{$\begin{array}{l}\text { General } \\
\text { Carneiro }\end{array}$} & $R_{\text {aj }}^{2}$ & 6 & 1 & 5 & 2 & 3 & 4 \\
\hline & $S_{y x \%}$ & 4 & 2 & 6 & 1 & 3 & 5 \\
\hline & $\mathrm{F}$ & 5 & 2 & 1 & 3 & 6 & 4 \\
\hline & VP & 15 & 5 & 12 & 6 & 12 & 13 \\
\hline \multirow{4}{*}{$\begin{array}{c}\text { Reseva } \\
\text { do Iguaçu }\end{array}$} & $R_{\text {aj }}^{2}$ & 6 & 1 & 3 & 2 & 5 & 4 \\
\hline & $S_{y x \%}$ & 4 & 1 & 3 & 2 & 5 & 6 \\
\hline & $\mathrm{F}$ & 5 & 3 & 1 & 2 & 6 & 4 \\
\hline & VP & 15 & 5 & 7 & 6 & 16 & 14 \\
\hline \multirow{4}{*}{ Paraná } & $R_{a j}^{2}$ & 6 & 1 & 5 & 1 & 1 & 4 \\
\hline & $S_{y x \%}$ & 6 & 1 & 5 & 2 & 3 & 4 \\
\hline & $\mathrm{F}$ & 4 & 2 & 1 & 3 & 6 & 5 \\
\hline & VP & 16 & 4 & 11 & 6 & 10 & 13 \\
\hline \multicolumn{2}{|c|}{ VP Total } & 97 & 43 & 55 & 52 & 101 & 89 \\
\hline
\end{tabular}

Fonte: os autores (2017) 
Na FIGURA 1, são apresentados os gráficos de resíduos padronizados da equação que apresentou o melhor ajuste em cada região. Para aquelas em que a EQUAÇÃO 2 não apresentou as melhores estatísticas, são apresentados os resíduos das equações que obtiveram os melhores VP e, ainda, os resíduos da EQUAÇÃO 2, objetivando a observação de possíveis diferenças nos resíduos que inviabilizassem a escolha dessa equação como o melhor modelo para cada região.

Observando-se o comportamento dos gráficos nas áreas em que a EQUAÇÃO 2 não apresentou isoladamente as melhores estatísticas (Araucária, Boa Ventura de São Roque e Coronel Vivida), verificou-se que o resíduo padronizado não apresentou diferenças significativas entre a EQUAÇÃO 2 e a equação de melhor ajuste nessas regiões, contribuindo com a decisão de escolher a EQUAÇÃO 2 como a mais adequada para representar todas as regiões.

Ainda, considerando o princípio da parcimônia (JATEGAONKAR, 2006), o qual infere que o número de parâmetros de um modelo não deve ser maior que o necessário para explicar o fenômeno analisado e, que o modelo deverá ser complexo o suficiente, porém o mais simples possível, pode-se eleger a EQUAÇÃO 2 como a mais adequada para representar as seis regiões, bem como a área do Paraná. Outro aspecto que justifica a escolha da EQUAÇÃO 2 é o fato de que em cinco áreas esta equação foi a que apresentou melhores resultados.
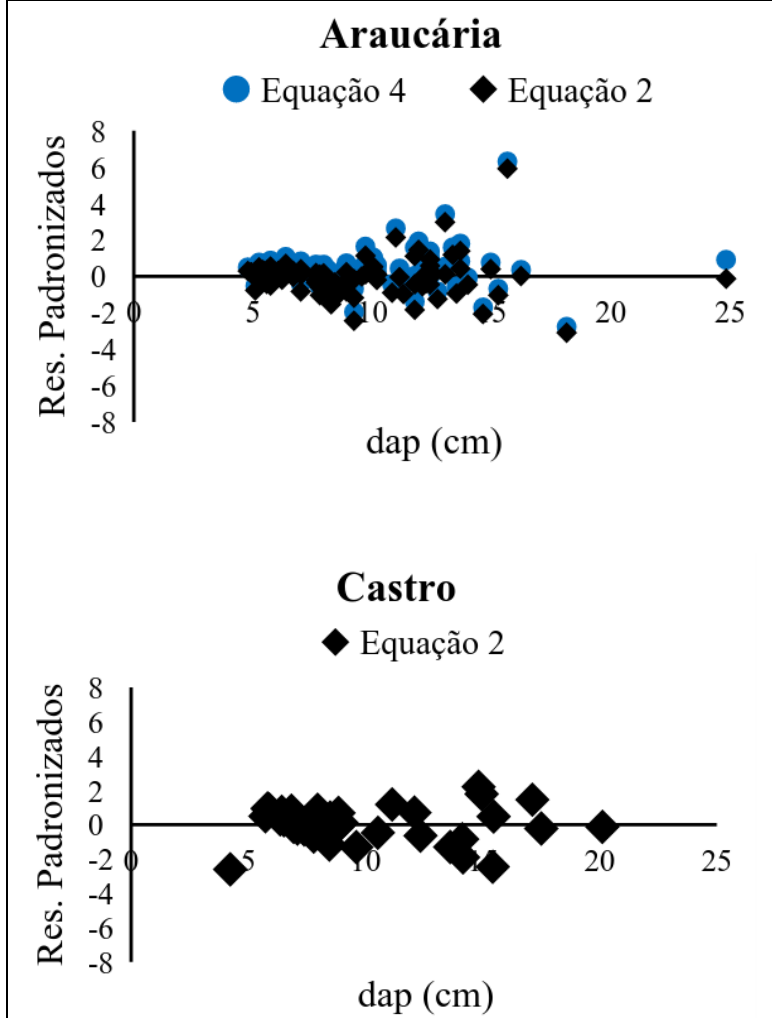
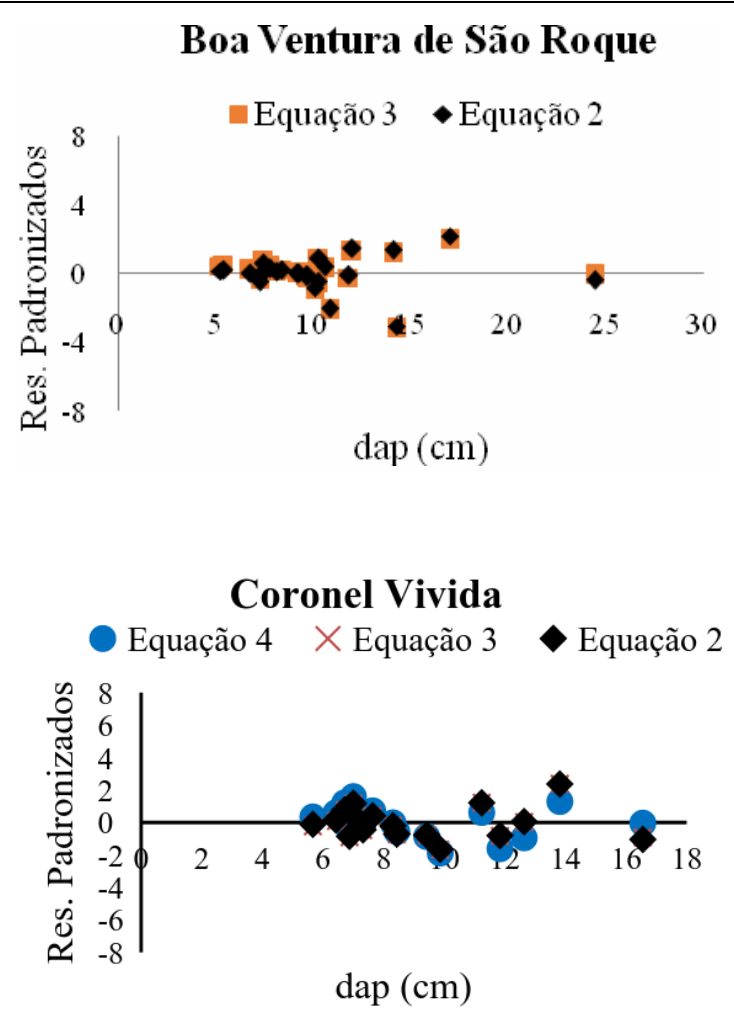


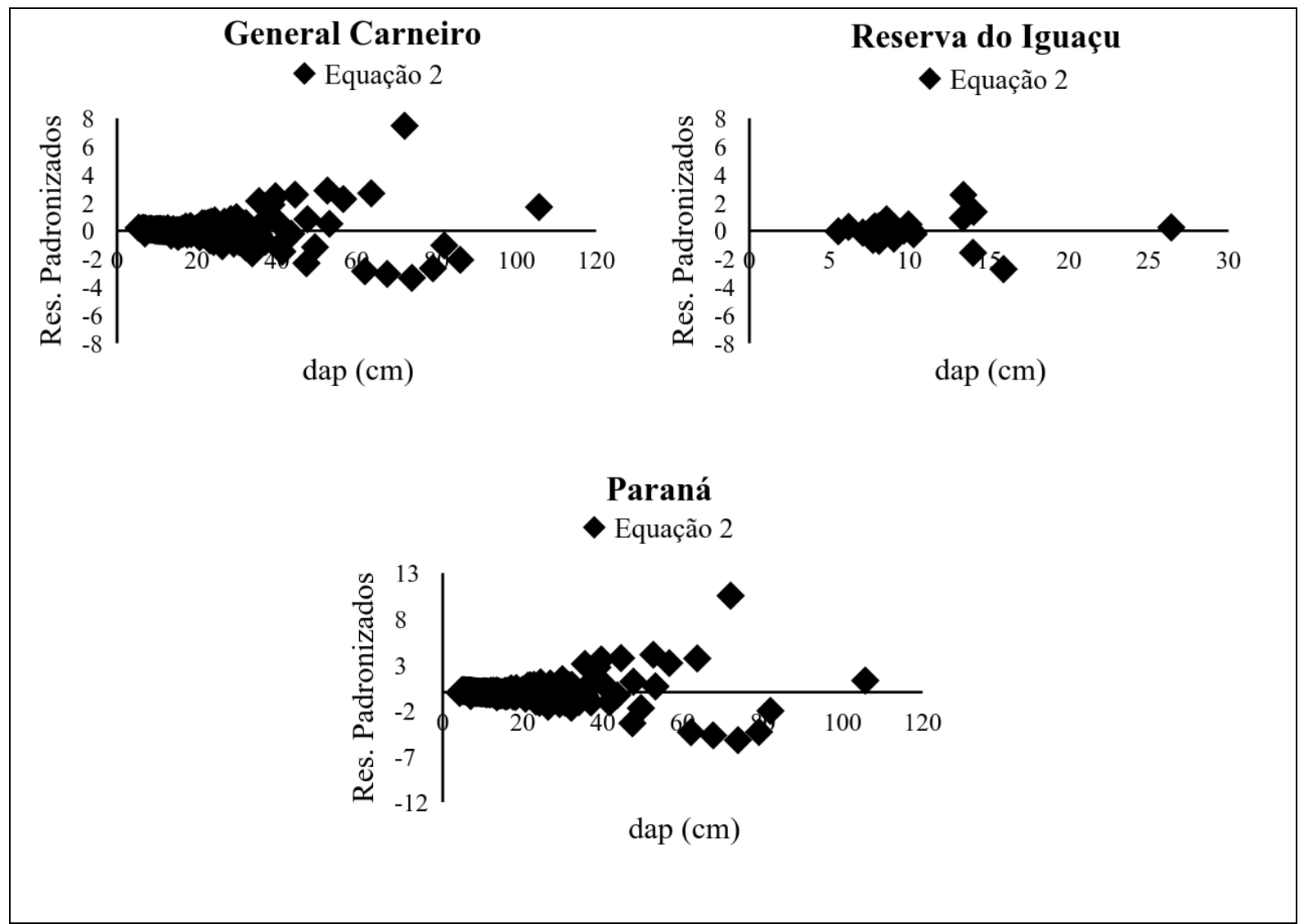

FIGURA 1 - Distribuição gráfica dos resíduos das melhores equações ajustadas para a estimativa da biomassa em seis regiões de floresta ombrofila mista no estado do Paraná. FONTE: Autores (2017)

A Tabela 2 mostra os resultados da EQUAÇÃO 2 ajustada para as seis áreas estudadas, bem como a equação do Paraná obtida com a junção das seis regiões, e suas estatísticas.

TABELA 2 - Resultado do ajuste da estimativa de biomassa da equação 2, em seis regiões de floresta ombrofila mista no estado do Paraná.

\begin{tabular}{l|l|c|c}
\hline Região & \multicolumn{1}{|c|}{ Equação 2 } & $R_{a j}^{2}$ & $S_{y x(\%:}$ \\
\hline Araucária & $B=13,338-3,764 \cdot$ dap $+0,527 \cdot$ dap $^{2}$ & 0,903 & 34,43 \\
Boa Ventura & $B=-13,893+3,982 \cdot$ dap $-0,047 \cdot$ dap $^{2}$ & 0,230 & 82,24 \\
Castro & $B=47,339-9,593 \cdot$ dap $+0,746 \cdot$ dap $^{2}$ & 0,867 & 34,95 \\
Coronel Vivida & $B=11,977-2,214 \cdot$ dap $+0,308 \cdot$ dap $^{2}$ & 0,638 & 48,15 \\
General & $B=112,624-14,323 \cdot$ dap $+0,688 \cdot$ dap $^{2}$ & 0,931 & 61,88 \\
Carneiro & $B=-1,371+0,380 \cdot$ dap $+0,263 \cdot$ dap $^{2}$ & 0,811 & 51,37 \\
Reserva do & $B=79,443-12,130 \cdot$ dap $+0,655 \cdot$ dap $^{2}$ & 0,928 & 85,83 \\
Iguaçu & $B$ Paraná &
\end{tabular}

FONTE: Autores (2017)

Considerando-se a escolha da EQUAÇÃO 2, pode ser observado ainda na FIGURA 2, que na área Paraná, a medida que se eleva o valor do dap, aumenta-se ENCICLOPÉDIA BIOSFERA, Centro Científico Conhecer - Goiânia, v.14 n.26; p.38 
a dispersão do resíduo, ou seja, o modelo estima com maior exatidão o comportamento da biomassa para árvores com baixo dap. Para melhor observação desse comportamento, a FIGURA 2 a seguir apresenta o histograma dos resíduos padronizados para diferentes faixas de dap.

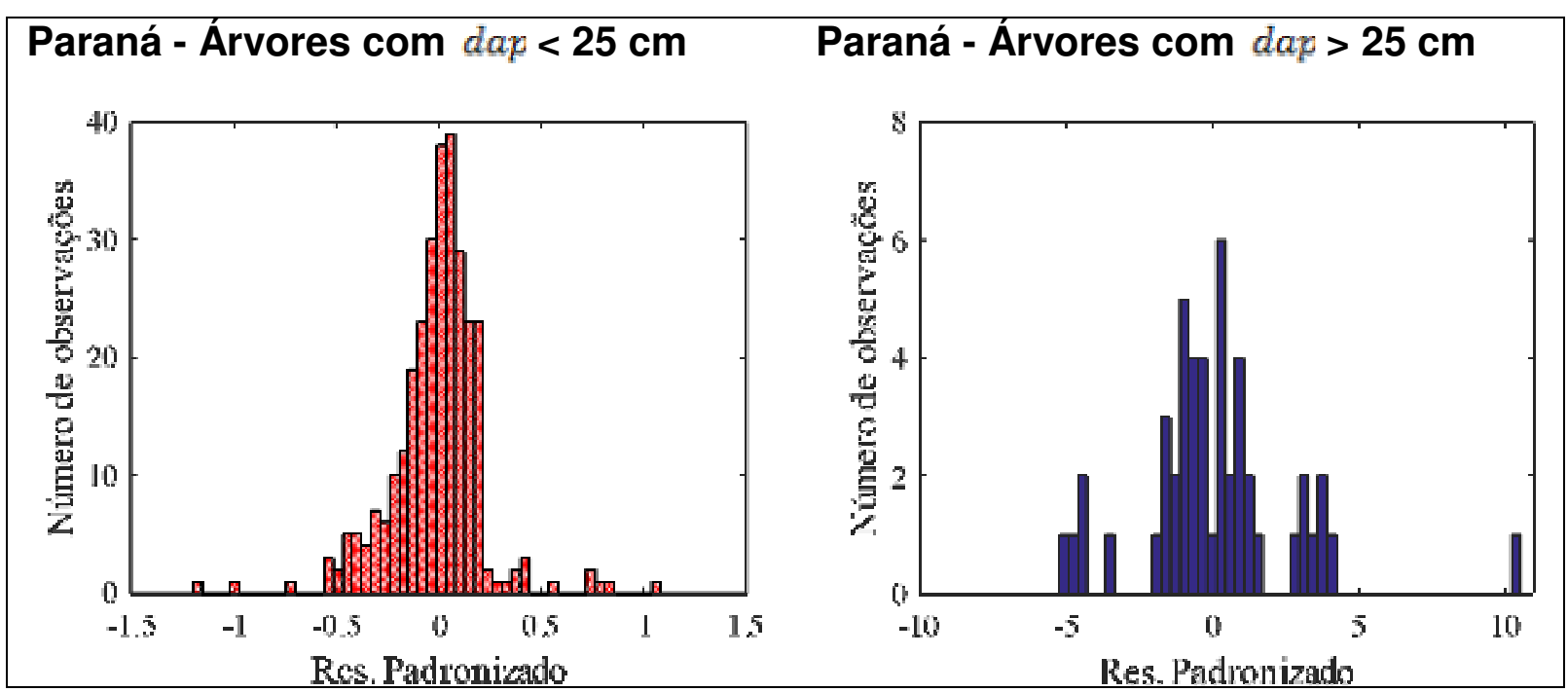

FIGURA 2 - Histograma dos resíduos para o modelo da área Paraná FONTE: Autores (2017)

O desvio padrão dos Resíduos para dap inferiores a $25 \mathrm{~cm}$ foi igual a 0,230 , enquanto que para dap superiores a $25 \mathrm{~cm}$ o desvio padrão foi de 2,637, ou seja, à medida que se eleva o valor do dap, aumenta-se a dispersão do resíduo. E assim, a equação estima com maior exatidão o comportamento da biomassa para árvores com baixo dap e estima a biomassa com menor exatidão para valores elevados do dap.

Quando avaliados os resultados apresentados na literatura, constatou-se que as estatísticas obtidas para os modelos estudados em cada região apresentaram valores semelhantes aos encontrados por Socher (2004) e Ratuchne (2015). Para o caso da região de Boa Ventura de São Roque, os valores obtidos nesse trabalho diferiram dos apresentados por Martins (2011). Todavia, destaca-se que nesse trabalho a seleção das seis equações candidatas considerou como variável independente única o dap, enquanto Martins (2011) apresentou o melhor modelo com dois regressores: dap e altura (h), justificando o melhor ajuste com 0 aumento da complexidade do modelo.

Para a realização da validação, nas áreas de Boa Ventura de São Roque, Castro, Coronel Vivida, e Reserva do Iguaçu, o número de indivíduos para cálculo da biomassa foi relativamente baixo (26, 42, 17 e 23 indivíduos, respectivamente), desse modo, não foi possível a separação dos dados em dois conjuntos: uma parte para ajuste e outra parte para validação. Assim, considerando a composição florestal única (Floresta Ombrófila Mista), e a distribuição das famílias e das espécies nas seis regiões estudadas, optou-se por utilizar as observações de outra região para a validação do modelo de determinada área, considerando que todas as áreas são parte da mesma Floresta Ombrófila Mista. Optou-se, dessa maneira, por utilizar os dados de diferentes áreas, escolhidas aleatoriamente, duas a duas, dentre as 15 combinações possíveis, para a validação dos modelos obtidos. Nesse processo, de modo a se evitar a extrapolação dos limites da variável independente do modelo em 
avaliação, os dados utilizados na validação respeitaram os intervalos dos dap da região em que foi realizado o ajuste do modelo.

A área de Araucária teve a equação validada nos dados de Boa Ventura de São Roque; a equação de Boa Ventura de São Roque nos dados de Coronel Vivida; assim como a equação da área de Castro foi validada nos dados de Araucária; equação de Coronel Vivida nos dados de Castro; equação de General Carneiro validada nos dados de Reserva do Iguaçu; e, por fim, equação de Reserva do Iguaçu validada nos dados da área de General Carneiro. Para a equação obtida na região de Araucária, verifica-se o comportamento aleatório do resíduo para dap inferiores a $15 \mathrm{~cm}$, demonstrando a boa capacidade preditiva da equação para árvores de pequeno porte. Todavia, verificou-se que para dap superiores a $15 \mathrm{~cm}$, representado por duas árvores no conjunto de validação, a equação superestimou o valor da biomassa. Essa característica decorreu do fato que na equação da floresta de Araucária, as árvores de grande porte, representadas em sua maioria por Gymnanthes klotzschiana Müll.Arg (branquilho), apresentam elevado valor de biomassa, enquanto que as árvores de grande porte na região de Boa Ventura de São Roque utilizadas na validação são uma Ocotea puberula (Rich.) Nees (canelacuiacá) e uma Dicksonia sellowiana Hook, (xaxim-sem-espinhos) caracterizadas por baixo valor de biomassa.

Para as demais regiões, os resíduos padronizados da validação não apresentaram tendências significativas, apresentando característica aleatória para as faixas de dap das equações de cada área analisada. Dessa maneira, comprovase a capacidade preditiva dos modelos obtidos para a EQUAÇÃO 2 para baixos valores de dap. A Tabela 3 apresenta os valores, mínimos, máximos e as médias, dos resíduos padronizados da validação.

TABELA 3 - Estatística dos resíduos padronizados da validação das áreas estudadas, duas a duas

\begin{tabular}{ccccc}
\hline Área & $\begin{array}{c}\text { Dados para } \\
\text { Validação }\end{array}$ & $\overline{\boldsymbol{X}}$ & Min. & Máx. \\
\hline Araucária & Boa Ventura & 16,62 & $-23,06$ & 174,94 \\
\hline Boa Ventura & Coronel Vivida & $-2,06$ & $-30,40$ & 13,74 \\
\hline Castro & Araucária & 1,69 & $-30,34$ & 55,68 \\
\hline Coronel Vivida & Castro & $-8,98$ & $-55,81$ & 6,72 \\
\hline $\begin{array}{c}\text { General } \\
\text { Carneiro }\end{array}$ & $\begin{array}{c}\text { Reserva do } \\
\text { Iguaçu }\end{array}$ & 15,91 & $-59,63$ & 44,57 \\
\hline $\begin{array}{c}\text { Reserva do } \\
\text { Iguaçu }\end{array}$ & $\begin{array}{c}\text { General } \\
\text { Carneiro }\end{array}$ & $-3,55$ & $-253,20$ & 146,20 \\
\hline
\end{tabular}

FONTE: Autores (2017). $\bar{x}$ : média; Min.: mínimo; Máx.: máximo.

A equação ajustada para todas as árvores (Paraná) foi validada nos $10 \%$ das amostras, sorteadas aleatoriamente entre as 382 árvores em estudo, ou seja, 38 foram separadas para validação.

A Figura 3 apresenta os resultados dos Resíduos Padronizados da validação para o Paraná, verifica-se com os dados de validação que a equação obtida para a área Paraná é representativa para árvores de pequeno porte, com dap inferiores a $25 \mathrm{~cm}$. Porém, para dap superiores a $25 \mathrm{~cm}$, o modelo não apresentou uma boa 
estimativa, subestimando os valores de peso da biomassa para as árvores de grande porte do conjunto de validação.

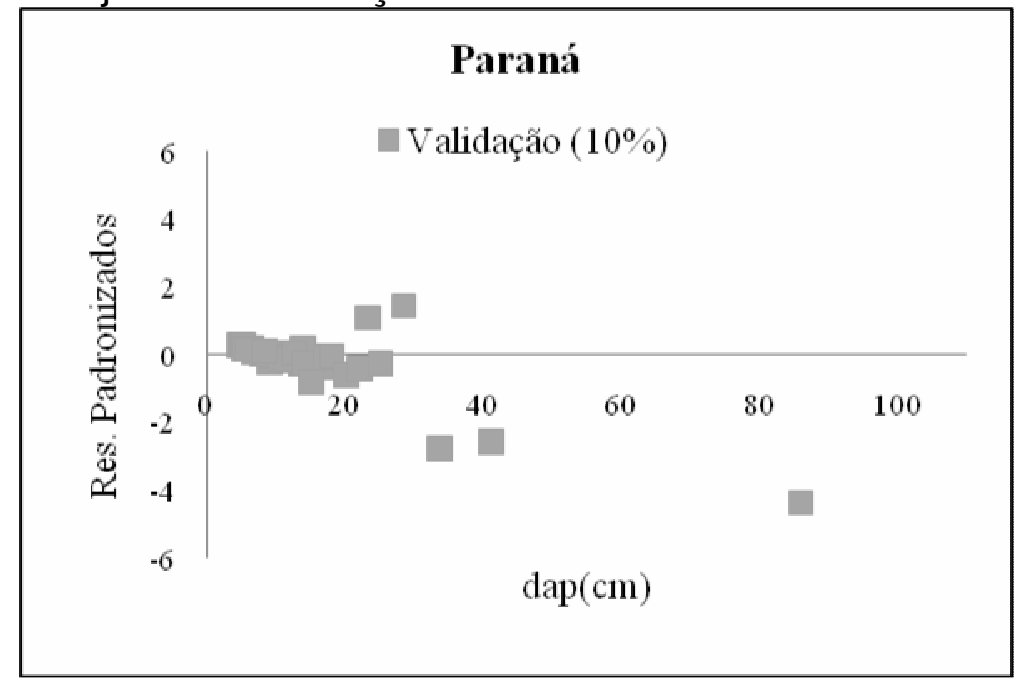

FIGURA 3 - Distribuição gráfica dos resíduos da validação da equação 2 para o Paraná

FONTE: Autores (2017)

\section{CONCLUSÃO}

Das seis regiões estudadas, duas delas, apresentaram estatísticas de ajuste relativamente baixos, isso deve-se a diversidade de espécies e o tamanho reduzido da amostra.

Nas demais áreas a maioria das equações avaliadas apresentou alto coeficiente de determinação ajustado e erro padrão da estimativa aceitável considerando que são equações para florestas naturais, podendo fornecer boas estimativas de biomassa.

Ao se considerar os valores ponderados (VP) dos escores, a análise dos resíduos e o princípio da parcimônia, selecionou-se a EQUAÇÃO 2 como a mais adequada para representar as regiões em estudo.

A equação que representa a junção das seis áreas é $B=79,443-12,130 \cdot d a p+0,655 \cdot$ dap $^{2}$ e foi denominada de "EQUAÇAO PARANÁ".

\section{REFERÊNCIAS}

ACCIOLY, $P$. Mapeamento dos remanescentes vegetais arbóreos do estado do Paraná e elaboração de um sistema de informações geográficas para fins de análise ambiental do estado. 2013. 129p. Tese (Doutorado em Engenharia Florestal) Universidade Federal do Paraná, Curitiba, PR.

BRASIL. Resolução no 2, de 18 de março de 1994. Define formações vegetais primarias e estágios sucessionais de vegetação secundaria, com finalidade de orientar os procedimentos de licenciamento de exploração da vegetação nativa do Paraná. Diário Oficial do União, Brasília, DF, n.059, 28 mar. 1994.

BROWN, S. Estimating biomass and biomass change of tropical forests. FAO Forestry paper - Forest Resources Assessment. 1997. 58 p. 
CARVALHO, J.L.N.; AVANZI, J.C.; SILVA, M.L.N.; MELLO, C.R.; CERRI, C.E.P. Potencial de sequestro de carbono em diferentes biomas do Brasil. Revista Brasileira de Ciência do Solo, v.34, p. 277-289, 2010. http://dx.doi.org/10.1590/S0100-06832010000200001

FIGUEIREDO FILHO, A.; DIAS, A. N.; STEPKA, T. F.; SAWCZUK, A. R. Crescimento, Mortalidade, Ingresso e Distribuição Diamétrica em Floresta Ombrófila Mista. Floresta, Curitiba, v. 4, n.4, p. 763 - 776, 2010. http://dx.doi.org/10.5380/rf.v40i4.20328

GOMES, J. F. Classificação e crescimento de grupos ecológicos na Floresta Ombrófila Mista da FLONA de São Francisco de Paula, RS. 2005. 75 f. Dissertação (Mestrado em Ciências Florestais) - Universidade Federal de Santa Maria, Santa Maria - RS, 2005.

IBGE. Manual técnico da vegetação brasileira. Rio de Janeiro: IBGE, 2012. 275p. JATEGAONKAR, R. Flight vehicle system identification: a time domain methodology, 1st ed. Reston, VA: AIAA Education Series, 2006.

KANIESKI, M.R.; ARAUJO, A.C.B.; LONGUI, S.J. Quantificação da diversidade em Floresta Ombrófila Mista por meio de diferentes índices alfa. Scientia Forestalis, 38: 567-577, 2010. 2 Disponível em < http://www.ipef.br/publicacoes/scientia/nr88/cap03.pdf>

KURCHAIDT, S. M. Uso de métodos estatísticos multivariados em dinâmica florestal. 2014. 106p. Tese (Doutorado em Engenharia Florestal) - Universidade Federal do Paraná, Curitiba, PR.

LONGHI, S.J. A estrutura de uma floresta natural de Araucaria angustifolia (Bert.) O.Ktze, no Sul do Brasil. Curitiba, 1980. 198f. Dissertação (Mestrado em Ciências Florestais) - Setor de Ciências Agrárias, Universidade Federal do Paraná.

MARTINS, P.J. Biomassa vegetal, estoque de carbono e dinâmica em um fragmento de Floresta Ombrófila Mista Montana. 2011. 86 f. Dissertação (Mestrado em Produção Vegetal) - Universidade Estadual do Centro-Oeste, Guarapuava, PR.

PIRES, P. T. L. de; ZENI JUNIOR, D. M.; GAULKE, D. As unidades de conservação e a Floresta Ombrófila Mista no estado do Paraná. Ciência Florestal, Santa Maria, v.22, n.3, p. 589-603, 2012. http://dx.doi.org/10.5902/198050986625

PIZATTO, W. Avaliação biométrica da estrutura e da dinâmica de uma Floresta Ombrófila Mista em São João do Triunfo - PR: 1995 a 1998. Curitiba: UFPR (Dissertação de Mestrado), 1999. 172p.

RATUCHNE, L. C. Equações alométricas para estimativa de biomassa, carbono e nutrientes em uma Floresta Ombrófila Mista. 2010. 111p. Dissertação (Mestrado em Agronomia) - Universidade Estadual do Centro Oeste, Guarapuava, PR. 
RATUCHNE, L. C. Biomassa e carbono: equações e dinâmica em fragmentos de Floresta Ombrófila Mista no Paraná. 2015. 102p. Tese (Doutorado em Engenharia Florestal) - Universidade Federal do Paraná, Curitiba, PR.

REGAZZI, A.J. Teste para verificar a identidade de modelos de regressão e a igualdade de alguns parâmetros num modelo polinomial ortogonal. Revista Ceres, Viçosa, v. 40, n. 228, p. 176-195, 1993. Disponível em < http://www.ceres.ufv.br/ojs/index.php/ceres/article/view/2190>

SANTOS, J. Análise de modelos de regressão para estimar a fitomassa da floresta tropical úmida de terra-firme da Amazônia brasileira. 1996. 121 p. Tese (Doutorado em Ciências Florestais), Universidade Federal de Viçosa.

SCHAAF, L.B. Florística, estrutura e dinâmica no período 1979-2000 de uma Floresta Ombrófila Mista localizada no sul do Paraná. Curitiba, 2001. 119p. Dissertação (Mestrado em Ciências Florestais), Curso de Pós-Graduação em Engenharia Florestal, Universidade Federal do Paraná.

SCHNEIDER, P.R. Análise de regressão aplicada à engenharia florestal. Santa Maria: UFSM, 1997.

SILVEIRA, P.;KOEHLER, H. S.;SANQUETA, C. R.;ARCE, J. E.O estado da arte na estimativa de biomassa e carbono em formações florestais. Floresta, Curitiba, v. 38, n. 1, p. 185-206, jan./mar. 2008. http://dx.doi.org/10.5380/rf.v38i1.11038

SONEGO, R. C.; BACKES, A.; SOUZA, A. F. Descrição da estrutura de uma Floresta Ombrófila Mista, RS, Brasil, utilizando estimadores não-paramétricos de riqueza e rarefação de amostras. Acta botânica Brasílica, Belo Horizonte. v. 21, n. 4, p. 943955, 2007. http://dx.doi.org/10.1590/S0102-33062007000400019.

THIERSCH, A. A eficiência das distribuições diamétricas para prognose da produção de Eucalyptus camaldulensis. Lavras, 1997. 155f. Dissertação (Mestrado em Engenharia Florestal) - Universidade Federal de Lavras, Lavras, 1997. 